\title{
Self-financed efficiency incentives: case study of Mexico
}

\author{
Anand R. Gopal • Gregory Leventis • Amol Phadke • \\ Stephane de la Rue du Can
}

Received: 22 June 2013 / Accepted: 26 March 2014 / Published online: 24 April 2014

(C) The Author(s) 2014. This article is published with open access at Springerlink.com

\begin{abstract}
Numerous countries use public funds to subsidize residential electricity for a variety of socioeconomic objectives. These subsidies lower the value of energy efficiency to the consumer while raising it for the government. Further, while it would be especially helpful to have stringent Minimum Energy Performance Standards (MEPS) for end uses in this environment, they are hard to strengthen without imposing a cost on ratepayers. In this second-best world, where the presence of subsidies limits the government's ability to strengthen standards, we find that efficiency-induced savings in subsidy payments can be a significant source of financing for energy efficiency incentive programs. Here, we introduce the Lawrence Berkeley National Laboratory (LBNL) Energy Efficiency Revenue Analysis (LEERA) model to estimate the greatest appliance efficiency improvements that can be achieved in Mexico by the revenue neutral financing of incentive programs from savings in subsidy payments yielded by the same efficiency improvements. We analyze Mexico's tariff structures and the long-run marginal cost of supply to calculate the marginal savings for the government from appliance efficiency. We find that these avoided subsidy payments
\end{abstract}

Electronic supplementary material The online version of this article (doi:10.1007/s12053-014-9263-9) contains supplementary material, which is available to authorized users.

A. R. Gopal $(\bowtie) \cdot$ G. Leventis $\cdot$ A. Phadke

S. de la Rue du Can

Environmental Energy Technologies Division, Lawrence

Berkeley National Laboratory,

1 Cyclotron Rd, Berkeley, CA 94720, USA

e-mail: argopal@lbl.gov alone can provide enough revenue to cover the full incremental manufacturing cost of refrigerators that are $29 \%$ more efficient and televisions that are $36 \%$ more efficient than baseline models. For room air conditioners (ACs), the same source of financing can contribute up to one third of the incremental manufacturing cost of a model that is $10 \%$ more efficient than baseline. We analyze the sensitivity of our results to the most important parameters and find our main conclusion that efficiency-induced avoided subsidy payments will contribute significantly to financing efficiency incentive programs in Mexico to be significant and robust.

Keywords Financial incentives · Energy efficiency · Developing countries $\cdot$ Energy subsidies $\cdot$ Appliance market transformation $\cdot$ Mexico

\section{Introduction}

Electricity consumption subsidies are common in countries around the world. While subsidies are found in OECD countries, the majority of subsidy programs are in developing countries, including the major emerging economies (Morgan 2008). In most of these countries, electricity and fuel subsidies were introduced as social programs to reduce the cost of energy for the poor (Komives et al. 2006). Hence, reducing or eliminating subsidies involves substantial political risk and is usually not part of the energy policy dialogue (2010). Further, subsidies make it harder to introduce or strengthen Minimum Energy Performance Standards 
(MEPS) for end uses, as greater stringency is frequently not cost-effective from the consumer perspective (Letschert et al. 2011).

Lawrence Berkeley National Laboratory (LBNL) is developing the LBNL Energy Efficiency Revenue Analysis (LEERA) model to help design incentive programs that meaningfully improve appliance efficiency with self-financing from efficiency-induced savings in subsidy payments. LEERA calculates the financial savings that will accrue to the government from the deployment of more efficient models for each type of appliance. It then draws on the product-specific technoeconomic analyses of the Super-efficient Equipment and Appliance Deployment (SEAD) Initiative, ${ }^{1}$ which calculate countryspecific incremental manufacturing costs of higher efficiency appliance models. These incremental costs and government financial savings are then compared to help incentive program designers understand the amount of self-financing that will be available at each level of appliance efficiency improvement. Where the amount of selffinancing available is greater than the program costs, an appliance incentive program could be entirely financed by avoided subsidy payments. The model can support several types of incentive program design.

The version of LEERA we present here can most effectively support policy in cases where revenue flows for electricity subsidies and end-use efficiency incentive programs are fungible, and decisions regarding funding allocations for either option rest with the same authority (i.e., the Government of Mexico). These conditions hold true in a large number of developing countries because there are no established funding mechanisms for efficiency incentive programs nor too many restrictions on sources of financing for them (Sarkar and Singh 2010). Therefore, this version of LEERA cannot directly support incentive program design in the USA and in many European countries where stricter policies govern the sources of financing for energy efficiency (Geller et al. 2006), although it can still identify incentive opportunities. In future improvements to the model, we plan to extend its applicability to cases common in the USA and Europe where decisions to invest in efficiency are made by privately owned utilities and their government regulators (Geller et al. 2006).

In this paper, we analyze refrigerators, televisions (TVs), and room air conditioners (ACs) for residential

\footnotetext{
${ }^{1}$ To learn more about the SEAD Initiative, please visit http:// superefficient.org
}

use in Mexico, a sector that receives generous net taxpayer-funded electricity subsidies (Komives et al. 2009). Our goal is to help Mexican regulators understand, precisely, the extent to which they can transform the markets for these major end-use appliances if revenue from avoided subsidy payments was to be used to finance incentive programs. The paper is structured as follows. We first present an overview of energy subsidies and the theory of their impact on demand for energy efficiency. Next, we introduce and explain the LEERA model. This is followed by a presentation and discussion of results for Mexico and their implication for appliance market transformation and financing for incentive programs. Finally, we discuss broader applications of LEERA.

\section{Energy subsidies and energy efficiency}

Studies of global energy subsidies find that they are substantial and most are in developing countries (Morgan 2008). Globally, approximately $\$ 420$ billion is spent annually on energy subsidies, making it one of the most subsidized sectors (Badcock and Lenzen 2010; Lewis 2012). Although most of these subsidies are for petroleum, substantial support is directed toward electricity consumption (Foster and Yepes 2006). In 2008, the UNEP estimated that the economic value of subsidies going to the electricity sectors in Russia, China, India, Saudi Arabia, and South Africa approached or exceeded $\$ 5$ billion per year in each country (Morgan 2008). Importantly, even though the stated goals of most subsidy programs are to reduce poverty, there is considerable evidence that they are not well targeted (Komives et al. 2006).

Despite the massive amounts spent on subsidies, there is a paucity of data on energy subsidy programs at the country level. Studies have lamented the lack of a global or even OECD-wide inventory of programs (Badcock and Lenzen 2010; Gadgil and Anjali Sastry 1994). Badcock and Lenzen undertook a comprehensive review of subsidies for energy generation, but they did not find a consistent definition of electricity subsidies, a consistent method of accounting for them, or a consistent method for estimating them (Badcock and Lenzen 2010). Even the European Union does not use a uniform evaluation method for each member country (Bacon et al. 2010). Part of the difficulty in evaluating and analyzing subsidies is the numerous forms that subsidies 
can take including direct cash transfers, tax credits, rebates, accelerated depreciation, cross subsidies, price caps, subsidized loans, waived dividends, risk assumption, or delayed system maintenance (Komives et al. 2005). Further, many countries, like India, have unplanned subsidies where government-owned utilities frequently recoup their losses from the general fund on an ad hoc basis (Abhyankar and Phadke 2012).

Improving energy efficiency in subsidized regimes

From an energy policy perspective, subsidies cause overconsumption of energy and lead to inefficient allocation of societal resources (2010). From an energy efficiency perspective, end-use electricity subsidies typically make efficiency programs more challenging to implement (Bouton et al. 2010). Even in the absence of subsidies, society underinvests in energy efficiency due to market failures like first-cost barriers, consumer information asymmetry, and environmental externalities caused by energy production and use (Jaffe and Stavins 1994; Meier and Jollands 2007). Figure 1 shows the deadweight loss resulting from these market failures if electricity is priced at the privately optimal marginal cost $\left(P_{\text {PRIV }}\right)$ instead of the socially optimal marginal $\operatorname{cost}\left(P_{\text {SOC }}\right)$.

Electricity subsidies further increase this deadweight loss. Figure 2 shows a market in which the price to consumers $\left(P_{\mathrm{SUB}}\right)$ for electricity is reduced below $P_{\text {PRIV }}$ due to subsidies. Electricity becomes even

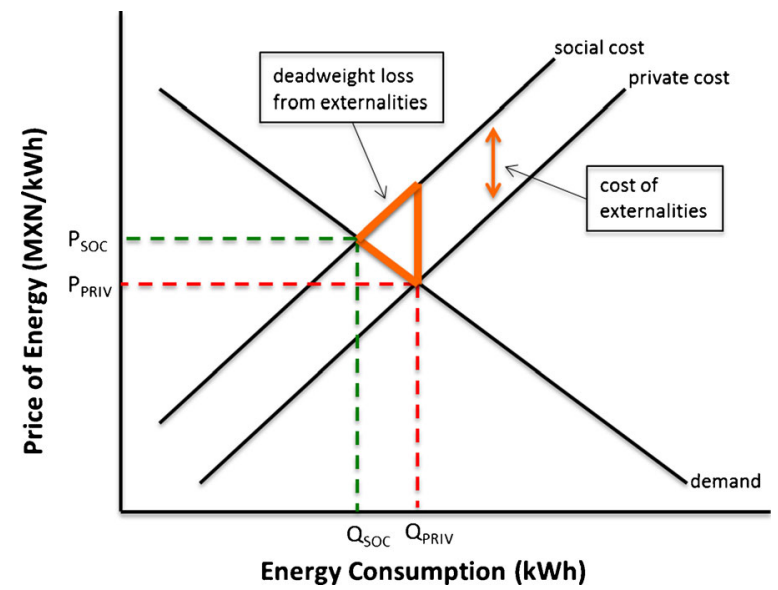

Fig. 1 Deadweight loss due to social externalities from electricity consumption without subsidized tariffs. $M X N$ Mexican Pesos, $P_{S O C}$ socially optimal price, $P_{P R I V}$ privately optimal price, $Q_{S O C}$ socially demanded quantity, $Q_{P R I V}$ privately demanded quantity, $k W h$ kilowatt hours

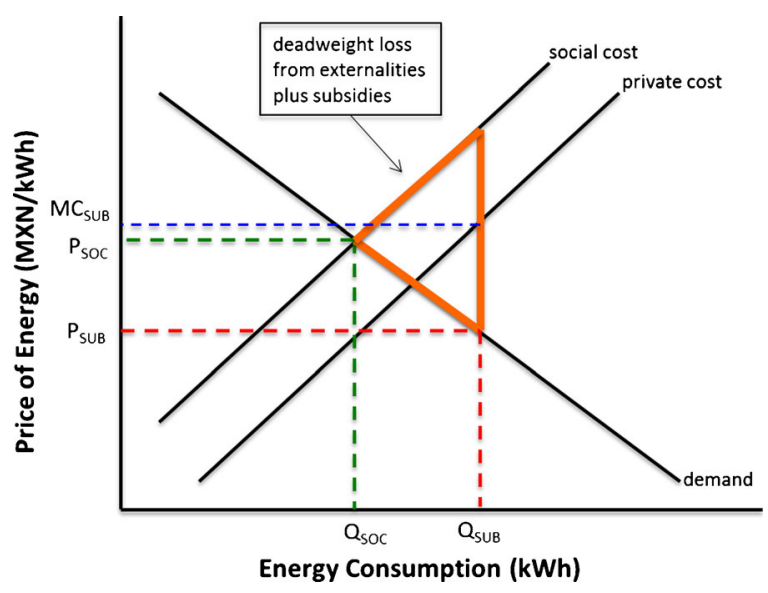

Fig. 2 Additional deadweight loss due to electricity consumption subsidies. $P_{S U B}$ subsidized electricity price, $M C_{S U B}$ marginal private cost under subsidized pricing and demand, $Q_{S U B}$ quantity demanded under subsidized pricing

cheaper compared to its socially optimal cost, resulting in even greater demand $\left(Q_{\mathrm{SUB}}\right)$. However, subsidies make energy efficiency more valuable to the government, which can decrease its subsidy burden by reducing end-use energy consumption. From a theoretical economic perspective, a rollback of subsidies would be a first-choice energy policy (Komives et al. 2009). However, as we discuss earlier, such policies have proven to be politically challenging (Bacon et al. 2010). This is because the government is not just concerned by economic efficiency but also by political reality and the need to maintain broad popularity. Financial incentives, on the other hand, are a politically feasible efficiency policy that can transform the market without any changes to existing subsidy program design. In the next section, we describe the methodology, assumptions, inputs, and sources of data for the LEERA model and explain how the model supports the design of incentive programs self-financed by appliance efficiency improvements.

\section{The LEERA model}

The objective of the LEERA model is to calculate the savings from avoided subsidy payments achieved by appliance energy efficiency and to treat these as revenues to finance incentives for the same efficient appliances. It does this by calculating the subsidy on the marginal unit of electricity consumed by a representative appliance-owning household, multiplying that by the annual energy savings from the deployment of a 
more efficient appliance, and calculating the present value of the associated subsidy payment savings over the life of the appliance. Using this approach, we generate a curve of government financial savings for each percentage improvement in appliance efficiency relative to the baseline efficiency. We can compare this curve of revenues from avoided subsidy payments to various types of incentive program costs. In this paper, we compare the avoided subsidy revenue curve to the incremental manufacturing cost curve.

In its avoided subsidy payment calculations, LEERA only includes subsidies that cover the difference between retail price and long-run marginal cost of generation because only this revenue is likely to be available for financing incentive programs. LEERA does not include efficiency-induced abatement of externalities in the avoided subsidy calculation because these are not real streams of revenue unless policies that regulate for externalities already exist. Hence, it can be argued that LEERA underestimates the overall subsidy burden of the government, because the government will most likely have to bear the long-run costs of social and environmental externalities. LEERA also ignores other forms of subsidies that are unplanned but frequent, like grants or interest-free loans to the utility for system upgrades, preferential tax rates to utilities, etc. Due to their ad hoc, unplanned nature, these are hard to quantify as efficiency-induced revenue streams available for incentives. However, all of these forms of subsidy payments will be reduced by improvements in appliance efficiency, which implies that we are underestimating the self-financing potential in our results.

First, the amount of money that the government avoids spending for each unit of electricity saved is calculated. This is done by calculating the difference between the tariff at which electricity savings are realized and the supply cost. LEERA assumes that appliance efficiency savings occur at the consumer margin, and hence, the model uses the following equation to calculate avoided subsidy payment per unit of electricity:

Avoided subsidy payment $(\$ / \mathrm{kWh})=$ long-run marginal cost of supply (LRMC) $(\$ / \mathrm{kWh})-$ marginal tariff at which electricity savings occur $(\$ / \mathrm{kWh})$.

The difference between $\mathrm{MC}_{\mathrm{SUB}}$ and $P_{\mathrm{SUB}}$ in Fig. 2 is the avoided subsidy payment calculated in the equation above.

Next, LEERA multiplies this avoided subsidy payment per unit by the annual electricity savings from deploying appliance models that are more efficient than the baseline model. Baseline models are determined in the SEAD technoeconomic analyses using market surveys and forecasts for each appliance in each SEAD country (Park et al. 2011; Shah et al. 2013). Please refer to the Electronic supplementary material, the SEAD technoeconomic reports, and the LBNL report in support of refrigerator MEPS revision for Mexico (Letschert et al. 2011; Park et al. 2011; Shah et al. 2013) for more details on the baseline models we use in our analysis. LEERA then takes the present value of these annual financial savings over the life of the appliance to get the full value, to the government, of avoided subsidy payments at each level of improved efficiency. These subsidy savings are then compared to the incremental manufacturing costs of more efficient appliance models. It is important to note that incremental manufacturing costs of higher efficiency appliances tend to drop over time as demand grows (Dale et al. 2009). Hence, the self-financed efficiency improvement potential could be greater than we estimated in this paper.

We also correct for rebound using estimates from literature (Davis et al. 2012; Gavankar and Geyer 2010; Maxwell et al. 2011; Nadel 2012). We apply an $11 \%$ ( $0 \%$ direct $+11 \%$ indirect) rebound for refrigerators and TVs and a $24 \%$ (13\% direct $+11 \%$ indirect $)$ rebound for room ACs. Note that by including indirect rebound, we are choosing an approach that is more conservative in counting energy savings than many other studies (Gavankar and Geyer 2010; Maxwell et al. 2011). This is another factor that reduces the self-financing potential for efficiency incentives we report in our results.

For example, a baseline refrigerator model in Mexico uses $480 \mathrm{kWh}$ per year (Letschert et al. 2011). Thus, switching to a $25 \%$ more efficient model would yield energy savings of $107 \mathrm{kWh}$ per year. ${ }^{2}$ We calculate the subsidy for refrigerator use by a representative household to be $\$ 0.14$ per $\mathrm{kWh}$, which translates to saved subsidy payments of $\$ 13$ per year. The net present value of this revenue stream, at a real discount rate of $4 \%$, over the course of the refrigerator's 15-year lifetime is $\$ 142$. The incremental cost to produce a model that is $25 \%$ more efficient than the baseline model is $\$ 107$ (Letschert et al. 2011). Therefore, an upstream government incentive could be set at a level that covers $100 \%$

\footnotetext{
${ }^{2}$ Twenty-five percent corrected for an $11 \%$ rebound effect results in a $22.25 \%$ actual savings. $480 \mathrm{kWh} \times 22.25 \%=106.8 \mathrm{kWh}$ saved per year.
} 
of the incremental cost of making a more efficient refrigerator and still leave \$35 in savings from avoided subsidy payments as a result of deploying the more efficient model in place of a baseline model.

In this paper, we present results for refrigerators, room ACs (split style), and TVs. We plan to extend the analysis to other appliances and countries, as cost curves for each are completed by the SEAD technoeconomic analyses. Baseline unit energy consumption (UEC) and incremental manufacturing costs for room ACs and TVs are from the SEAD technoeconomic analysis (Park et al. 2011; Shah et al. 2013). For refrigerators, we use data from LBNL's analysis in support of harmonization of Mexican and US refrigerator standards (Letschert et al. 2011). The discount rate we use is from the SEAD technoeconomic analyses for each country (Shah et al. 2013).

\section{Applying LEERA to Mexico}

For this paper, we apply LEERA to the Mexican residential electricity sector. The state-owned utility, Comisión Federal de Electricidad (CFE), provides all residential electricity in Mexico. Rates are set by a complex increasing block tariff (IBT) system in which tariff zones are defined by average regional temperature (CFE 2012a). For electricity generation, fuel oil makes up $18 \%$ of the electricity generation mix and usually operates on the margin because it is the most expensive form of generation (Sicilia Salvadores and Horst Keppler 2010; 2012a). In this section, we describe how LEERA calculates the long-run marginal cost (LRMC) of generation and the marginal tariff at which savings occur for each appliance in Mexico.

TVs and refrigerators have almost $100 \%$ residential penetration rates (Davis et al. 2012; Komives et al. 2009). Hence, the LEERA model calculates marginal tariffs of households that own these two appliances by taking the average, seasonally adjusted customer electricity consumption for each residential tariff zone and applying the tariff rate at that consumption level (CFE 2012a). These marginal tariffs for each zone are then weighted by the zone's proportion of all customers (CFE 2012b) to get a nationally representative marginal tariff at which savings from more efficient refrigerators and TVs will occur.

LEERA calculates the marginal tariff for room ACs differently because they are only present in $39 \%$ of households and their use is greater in hotter regions where consumers are subsidized more heavily. From SEAD UEC data (Shah et al. 2013) and IEA data on
Mexican household share of AC energy consumption (Ellis 2009), LEERA calculates the minimum energy consumption of an AC-owning household. The model then uses this consumption level to determine which households in each tariff zone have ACs and their corresponding marginal tariff. A nationally representative AC marginal tariff is determined by taking an average of the marginal $\mathrm{AC}$ tariffs in each zone weighted by the number of AC-owning households in each zone. For more details on the calculation of AC marginal tariffs, please refer to the Electronic supplementary material.

Given fuel oil's significant share of the generation mix (18\%), a $64 \%$ capacity factor (IEA 2012), and because fuel oil generators almost always operate on the margin due to their high costs, it is sound to assume that these plants will be the marginal generators for efficiency savings. Even if the incentive programs we propose in this paper are extremely successful, they are unlikely to reduce total Mexican electricity demand by $18 \%$, which is the level necessary to completely avoid the need for fuel oil generators. Hence, it would be sufficient to just include the cost of fuel oil generation when calculating the LRMC in LEERA. However, because the share of fuel oil generation is expected to gradually drop over the coming two decades (Komives et al. 2009; 2012b), we make the conservative assumption that $10 \%$ of the longrun margin will be from substantially cheaper natural gas generation. This assumption reduces the revenues from avoided subsidy payments calculated by LEERA and therefore reduces the self-financing efficiency potential in our results.

To calculate the cost of fuel oil generation, LEERA uses its opportunity cost: the international market price. This is necessary because the prices charged for fuel oil by the state-owned oil company Pemex to the stateowned utility CFE are not public. In any case, it is very likely that Pemex would sell any fuel oil not needed for power generation at market price, probably to international shipping companies that use Mexican ports. Since Pemex is state-owned, this fuel oil sale revenue that results directly from improved appliance efficiency will accrue to the government. We use the 2012-2022 average of the reference forecast fuel oil price from the Annual Energy Outlook 2013 to calculate the long-run variable cost of generation (AEO 2013). Based on power plant efficiencies, this translates to a variable generation cost of approximately US $\$ 0.22$ per kWh (Badcock and Lenzen 2010; Honorio 2003; Lewis 2012). We correct this generation cost for transmission and distribution 
losses, approximately $17 \%$ in Mexico (2012b), to calculate the LRMC of end-use delivered fuel oil electricity. The same procedure is used to calculate the LRMC of natural gas generation where we again use the Annual Energy Outlook 2013 reference forecast of natural gas prices for electricity generation (2013). Assuming a generous power plant efficiency of $49 \%$ (Honorio 2003; Sicilia Salvadores and Horst Keppler 2010), this translates to a variable natural gas generation cost of US $\$ 0.04$ per $\mathrm{kWh}$ after adjusting for transmission losses. Since fossil fuel prices tend to be volatile, we analyze the sensitivity of our final results to oil and natural gas prices by including calculations for low and high EIA price scenarios. Finally, we do not include any fixed costs in our LRMC calculation. If we were to include the fixed costs, which are typically more than double the variable costs for marginal generators, we would find greater incentive self-financing potential in our final results.

For readers interested in more detail, please refer to the Electronic supplementary material where we have provided the entire LEERA Mexico analysis and data in spreadsheet form.

\section{Results}

We find that efficiency-induced savings in subsidy payments could finance incentives that cover the entire incremental manufacturing cost of refrigerators that are $29 \%$ more efficient than baseline models. In the case of LED-LCD TVs, the full incremental cost of models that are $36 \%$ more efficient than baseline models could be financed with just half of the savings from avoided subsidy payments. For room ACs, revenue from avoided subsidies could finance an incentive that would cover about one third of the incremental manufacturing cost of a $10 \%$ efficiency improvement (see Figs. 3, 4, and 5). Of all the principal input parameters in this analysis, we find that forecasts of oil and natural gas prices are the main parameters with uncertainty levels high enough to significantly change our results. Hence, we assess the sensitivity of our results for each appliance and find that our main conclusions are qualitatively robust (see Figs. 6, 7, and 8). We discuss our findings for each appliance below.

\section{Refrigerators}

The substantial market transformation potential we find for Mexican refrigerators is due to three main reasons: the large subsidies on each unit of refrigerator energy consumption, relatively high annual UEC, and the long life of the appliance. First, because refrigerators are owned by most households, rich or poor in all tariff zones, energy savings from more efficient models occur, on average, at highly subsidized tariff rates, thereby yielding more monetary savings to the government. Second, the UEC for refrigerators is high with no direct rebound. This is because refrigerators are always plugged in and are in continuous operation. Thus, any increase in efficiency translates to substantial annual energy savings. Finally, refrigerators have long lifetimes (15 years), so the large annual monetary and energy savings continue over a long time period. For these reasons, we find that efficiency-induced subsidy savings can yield revenue equal to the incremental manufacturing cost of refrigerator models that are $29 \%$ more efficient than baseline models (see Fig. 3). Figure 3 also shows that if an upstream incentive program was implemented that covered the full incremental cost difference for every model up to $29 \%$ more efficient than baseline, the total income from subsidy savings would actually be greater than the expenditures on incentives. This net positive revenue could be used to cover other costs (administrative, management, etc.) of implementing the program.

\section{LED-LCD televisions}

Currently, LED-LCD TVs have low market penetration in Mexico but are expected to constitute nearly $95 \%$ of the national stock within a decade (Park et al. 2011). Almost all new purchases today are LED-LCD models (Park et al. 2011). Therefore, in our analysis, we choose an already efficient LED-LCD TV as our baseline model. Further, TV UEC is substantially lower than refrigerators yielding less annual revenue potential from subsidy savings. We still find the market transformation potential for TVs to be greater than refrigerators for two reasons. First, two technologies, Dual Brightness Enhancement Film (DBEF) and Local Dimming, substantially increase LED-LCD TV efficiency at low $\operatorname{costs}^{3}$ (Park et al. 2011). Second, TV energy savings also occur at the same highly subsidized tariff rates as

\footnotetext{
${ }^{3}$ For more information on DBEF and Local Dimming technologies, please refer to the SEAD TV Analysis that can be found here: http://www.superefficient.org/Activities/Technical\%20Analysis/ SEAD\%20TV\%20Analysis.aspx
} 
Fig. 3 Revenue potential from avoided subsidy payments and incremental manufacturing costs for refrigerators

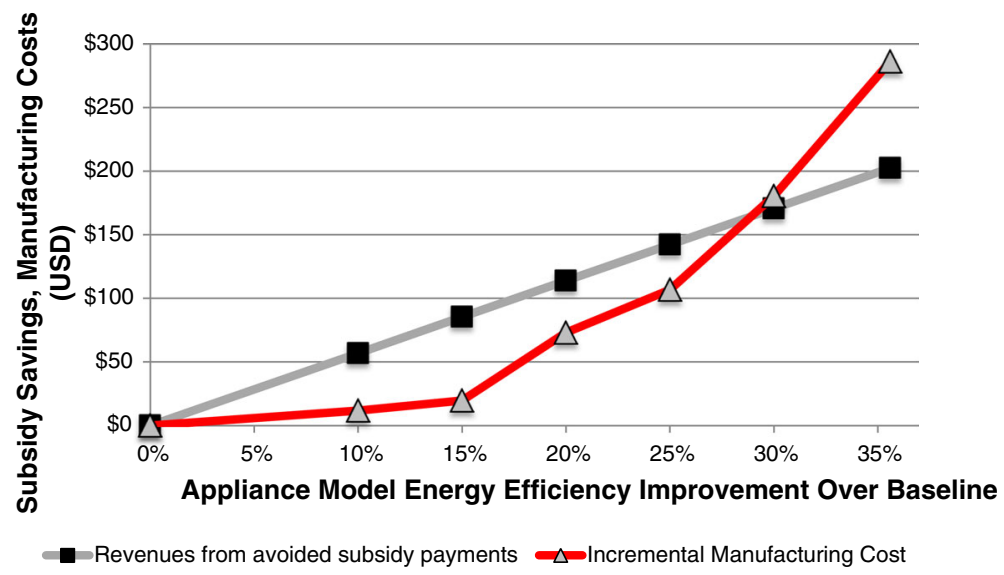

refrigerators since both appliances are similarly distributed among households. Figure 4 shows that TV efficiency-induced subsidy savings can yield revenue that is substantially greater than the incremental manufacturing cost of all super-efficient LED-LCD TV models. Note that we would see even greater potential if we set the baseline TV model to reflect today's market average efficiency in Mexico. Such a baseline would be appropriate to support the design of an early replacement incentive program. In this case, however, we choose to show a result that can support the design of an upstream program targeting only new purchases. Finally, it is important to keep in mind that further increases in TV efficiency involve a fundamental technological shift (i.e., OLED TVs) (Park et al. 2011), and hence, we should not assume that the two curves we see in Fig. 4 will continue to diverge at higher efficiency improvements, as the costs of OLED TVs are very uncertain at this time (Park et al. 2011).

\section{Room ACs}

Room ACs differ from TVs and refrigerators in two ways that reduce their market transformation potential in this analysis. First, improved AC efficiency yields less than half the savings from avoided subsidy payments when compared to TVs and refrigerators. This is because AC savings occur, on average, at less subsidized tariff rates. Second, studies have shown that AC efficiency improvements result in larger rebound, especially for households in hot regions, although the effect is weaker in wealthier households (Davis et al. 2012). So, we use a rebound value for ACs of $24 \%$ (13\% direct $+11 \%$ indirect) based on estimates in the literature
Fig. 4 Revenue potential from avoided subsidy payments and incremental manufacturing costs for TVs

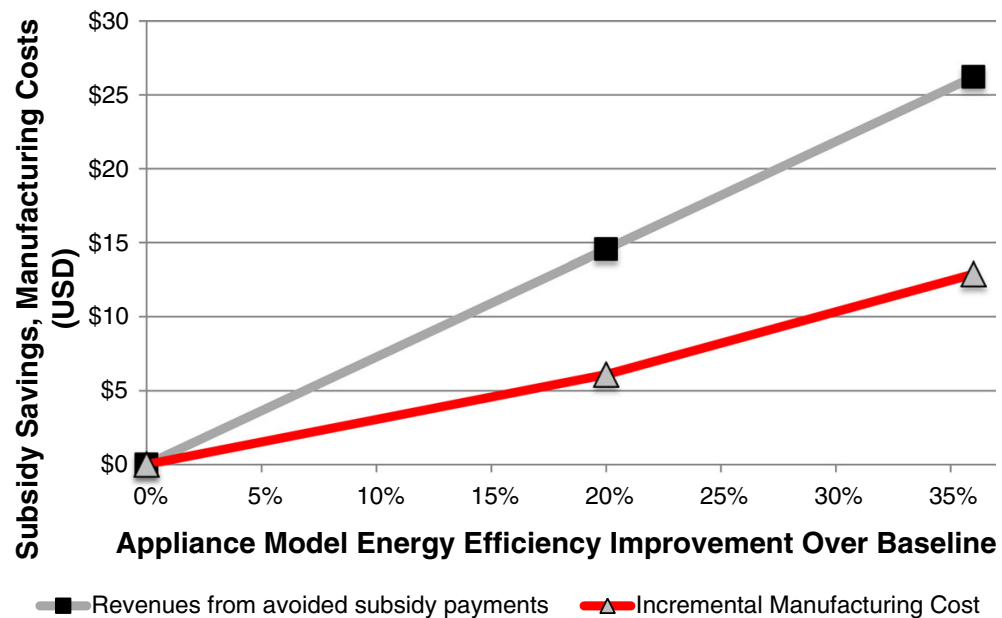


Fig. 5 Revenue potential from avoided subsidy payments and incremental manufacturing costs for room air conditioners

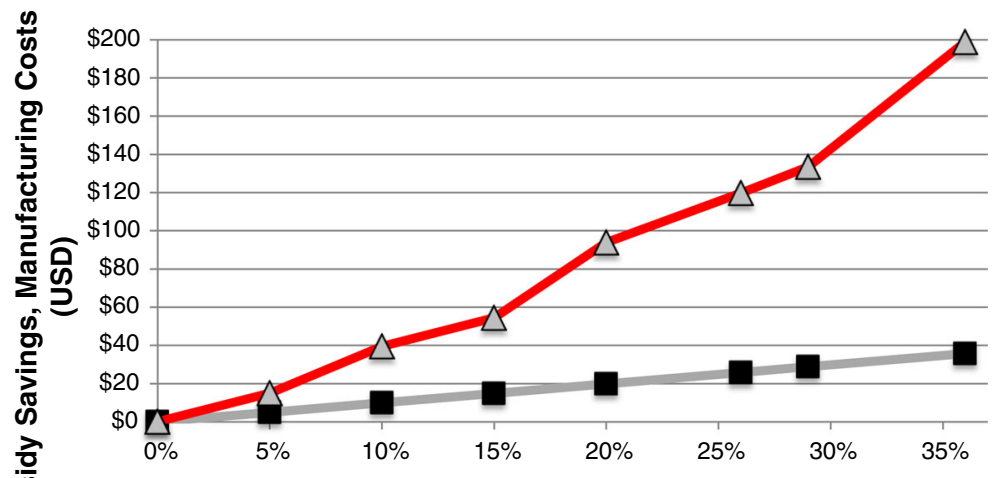

Appliance Model Energy Efficiency Improvement Over Baseline

Revenues from avoided subsidy payments $\Delta$ Incremental Manufacturing Cost that account for these effects (Maxwell et al. 2011; Nadel 2012). Therefore, even with high baseline consumption and a relatively long life $(582 \mathrm{kWh}$ per year, 12 years), Fig. 5 shows that AC efficiency-induced savings in subsidy payments do not yield enough revenue to cover the entire incremental manufacturing cost of more efficient room AC models. However, Fig. 5 also shows that avoided subsidy revenue would be sufficient to contribute one third of the incremental manufacturing cost of a model that is $10 \%$ more efficient than the baseline. Note that $\mathrm{AC}$ use is a much greater contributor to daily peak demand than refrigerators or TVs. Hence, inefficient ACs cost CFE, and therefore, the government a lot more than just electricity consumption subsidies in the long run. Therefore, the long-run savings that result from better power system planning due to improved AC efficiency could be a second source of financing for an $\mathrm{AC}$ incentive program.

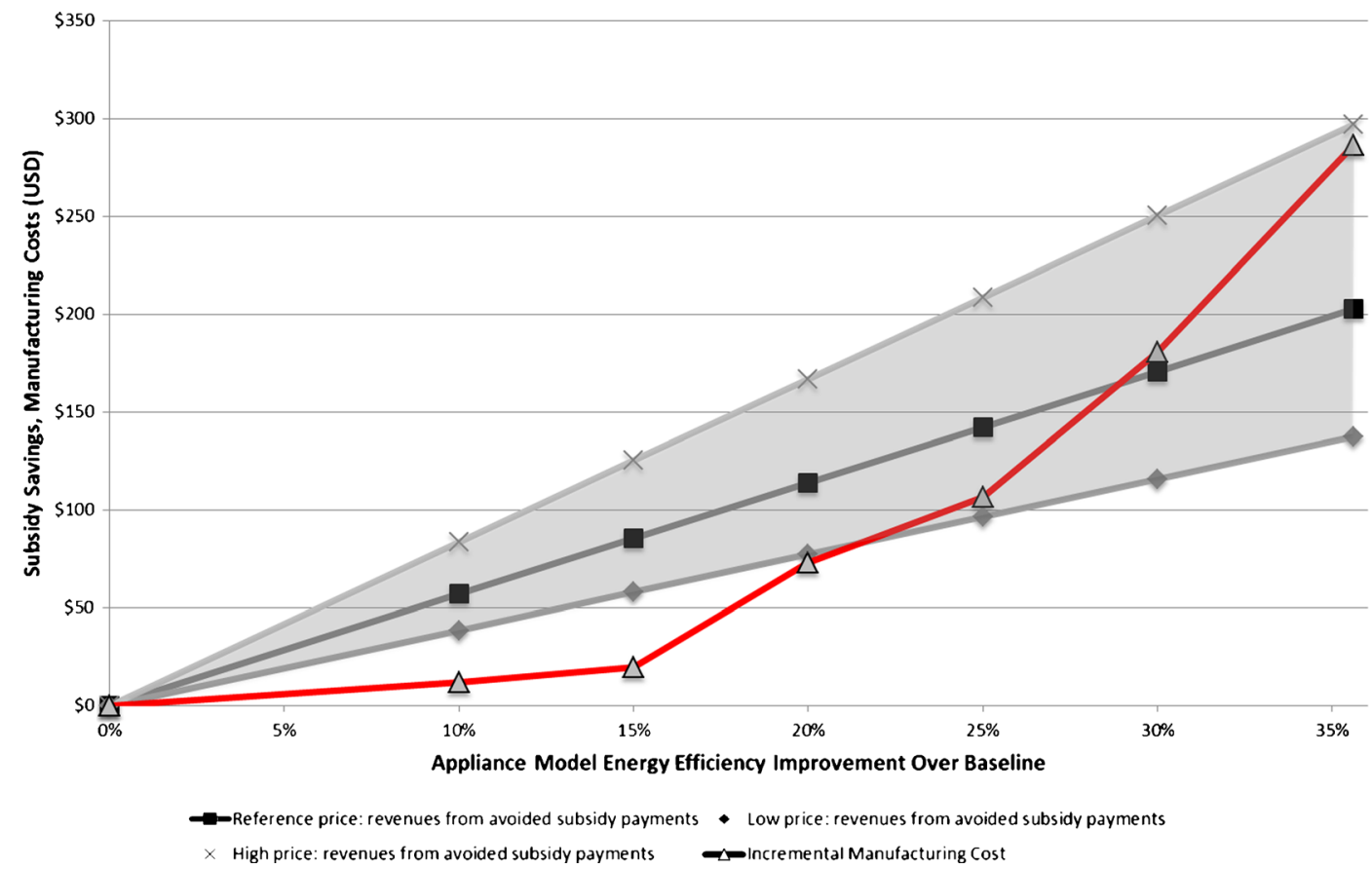

Fig. 6 Revenue potential sensitivity analysis for refrigerators 


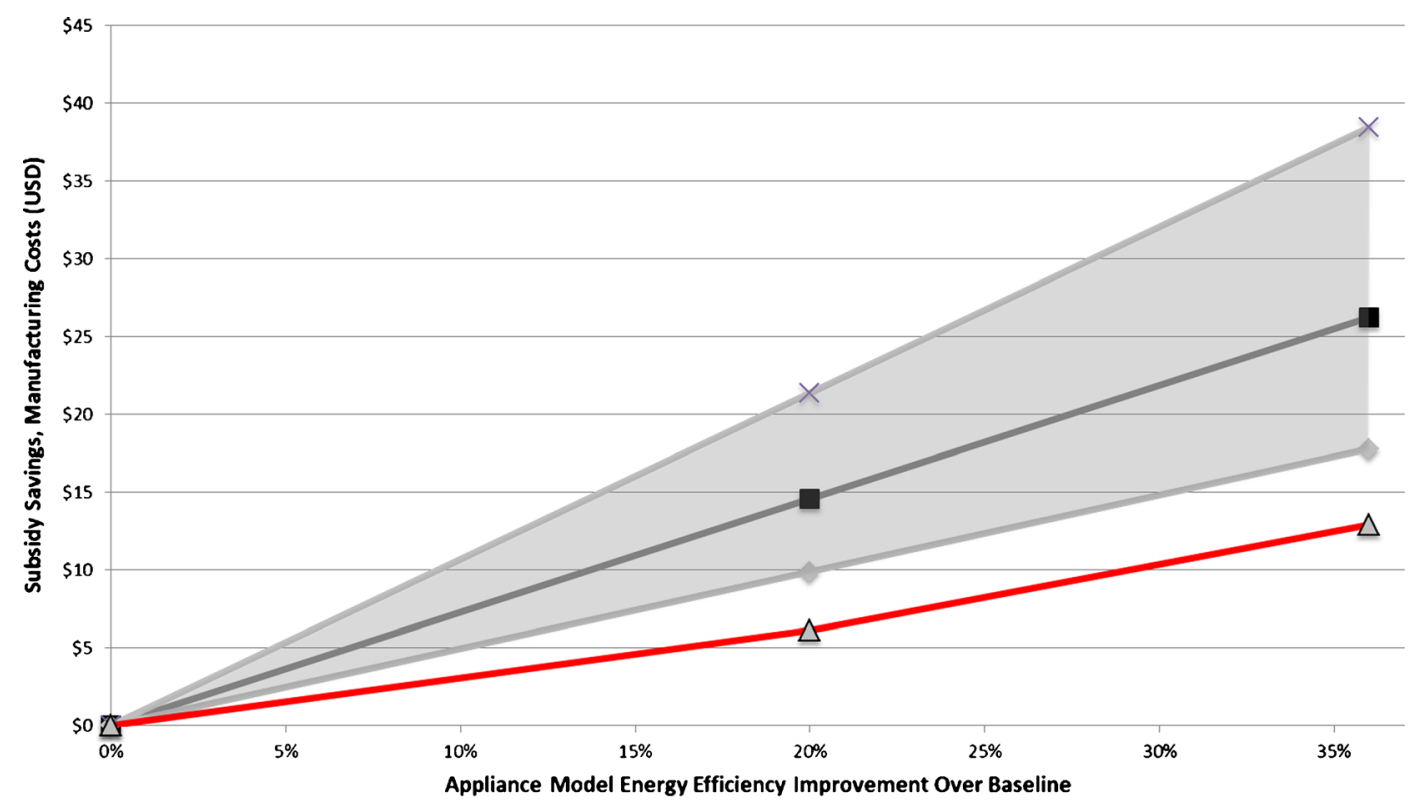

-Reference price: revenues from avoided subsidy payments $\leadsto$ Low price: revenues from avoided subsidy payments

$-x$ High price: revenues from avoided subsidy payments $\quad-\Delta$ incremental Manufacturing Costs

Fig. 7 Revenue potential sensitivity analysis for TVs

Sensitivity analysis: model input parameters and uncertainty

As with any model, LEERA includes assumptions and choices, both parametric and epistemic, the most important of which we explain and justify in the earlier section describing the model. However, it is important to assess the sensitivity of our main findings to uncertainties in key input variables to see if our conclusions could be fundamentally different. In order to decide

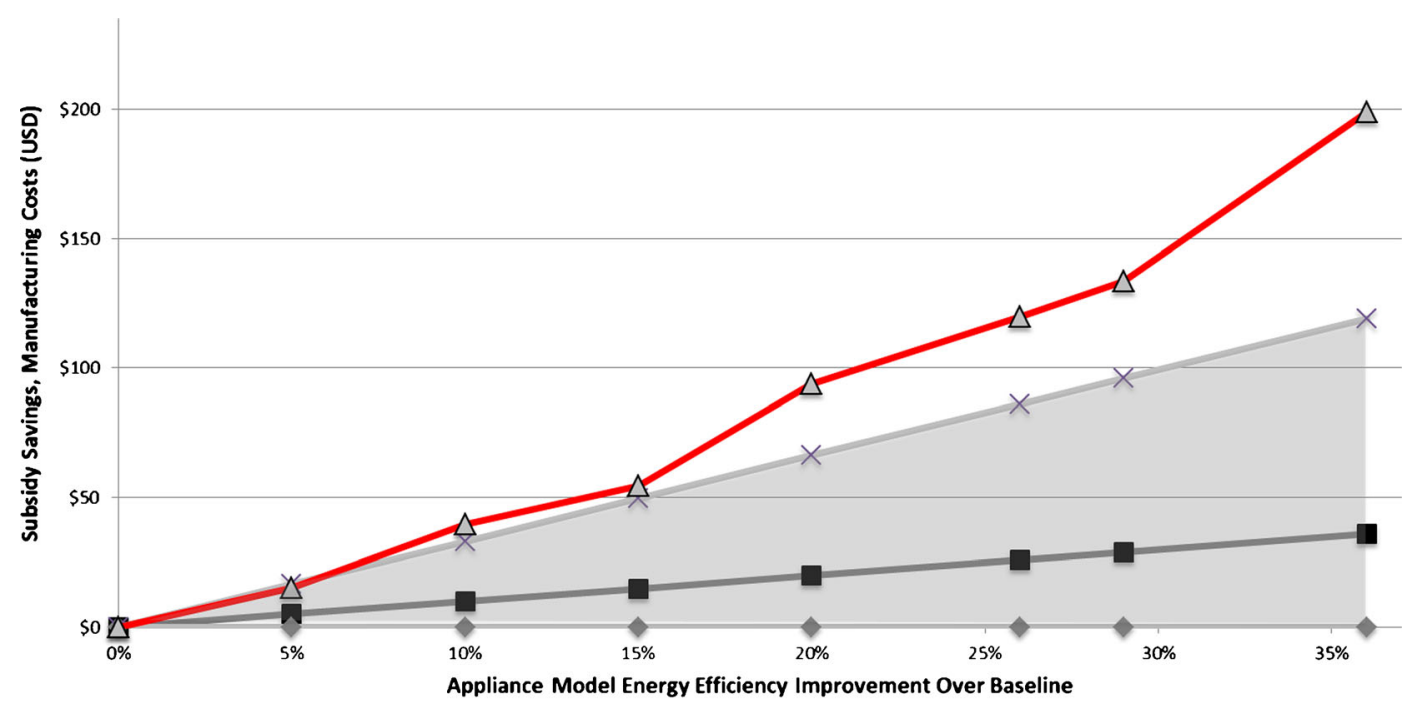

- Reference price: revenues from avoided subsidy payments $\Rightarrow$ Low price: revenues from avoided subsidy payments

$x$ High price: revenues from avoided subsidy payments $\quad \Delta-$ Incremental Manufacturing Cost

Fig. 8 Revenue potential sensitivity analysis for room air conditioners 
where to focus our sensitivity analysis, we compile a summary of key model input parameters, their sources, our understanding of uncertainty in each, and the qualitative effect of changes in each parameter on the market transformation potential of incentives financed by efficiency-induced subsidy savings (shown in Table 1).

LEERA's input parameters can be separated into one of three categories based on the parts of the analysis that each parameter influences. The three categories are the following:

1. Electricity generation and supply cost calculation

2. Calculation of tariffs at which efficiency savings occur for each appliance

3. Costs, use, and behavior related to each appliance

In the first category, the variables with the highest uncertainty are the price forecasts for fuel oil and natural gas. There are low levels of uncertainty regarding the long-run marginal fuel mix for reasons that we explain in the earlier section describing the model. Still, we choose a conservative value for the fuel mix that diminishes our revenue estimates so any sensitivity analysis on this parameter will only further enhance our conclusions. In the second category, there is medium uncertainty in the ratio of summer to winter consumption for a representative household because this ratio is estimated based on the difference in IBT consumption thresholds for each season and not from empirical data (for more information refer to the Electronic supplementary material). In the third category, there is a medium degree of uncertainty in the magnitude of the rebound effect, but because we use a value close to the highest estimates of rebound from the literature, sensitivity analyses on this parameter will only show greater efficiency improvement potential. All the other parameters have low to negligible uncertainty. Hence, from Table 1, we conclude that uncertainties in fuel oil and natural gas price forecasts are the most likely to qualitatively change our conclusions. When we apply LEERA to other countries, we expect fossil fuel price forecasts to be the most uncertain parameters in those cases as well.

We run our analysis for the low and high EIA price scenarios for fuel oil and natural gas to assess the sensitivity of our results to these price forecasts (2013). Figures 6,7, and 8 show that our main findings for each appliance are qualitatively robust. Recall from the section describing the model that our choices on what to exclude when calculating subsidy levels and the longrun marginal supply cost, the high values we use for rebound and the share of natural gas on the margin all reduce self-financing potential for efficiency incentives further underlining the significance and robustness of our findings. Even if prices of fuel oil and natural gas remain low over the next decade, we still see substantial revenue-neutral market transformation potential for TVs and refrigerators. Conversely, if the high price projections come to pass, we see $15 \%$ revenue neutral efficiency improvement potential for room ACs and greater than $36 \%$ improvement potential for refrigerators and TVs.

Figure 6 shows that efficiency-induced subsidy savings can still yield revenue equal to the incremental manufacturing cost of refrigerator models that are $20 \%$ more efficient than baseline models even if fuel oil and natural gas follow the EIA low price scenario. If these commodities follow the high price scenario, efficiency-induced subsidy savings will yield enough revenue to finance incentives for models that are $36 \%$ more efficient than baseline. Hence, we find that the case for a self-financed refrigerator incentive program in Mexico is strong and robust.

Figure 7 shows that our results for TVs are even more robust than for refrigerators. In all fuel oil and natural gas price scenarios, the efficiency-induced subsidy savings are greater than the full incremental cost of an LEDLCD TV that is $36 \%$ more efficient than baseline. Hence, our analysis makes a strong, robust case that a TV incentive program can be largely self-financed by the efficiency-induced subsidy savings in Mexico

Figure 8 shows that if the EIA's low price scenario for fuel oil and natural gas materializes, it could completely eliminate the Mexican government's subsidy burden at the tariff rate where savings from ACs occur. Hence, AC energy savings will not yield revenue from savings in subsidy payments. However, if the high price scenario occurs, we find that subsidy savings revenue would almost equal the incremental cost of a model $15 \%$ more efficient than baseline. When this revenue is coupled with the other benefits from AC efficiency improvements that we discuss in the $\mathrm{AC}$ result subsection, the Mexican government could finance an $\mathrm{AC}$ incentive program that can lead to significant market transformation. In summary, our conclusion that the self-financing potential for AC incentives in Mexico is small and significantly lower than for TVs and refrigerators is robust. 


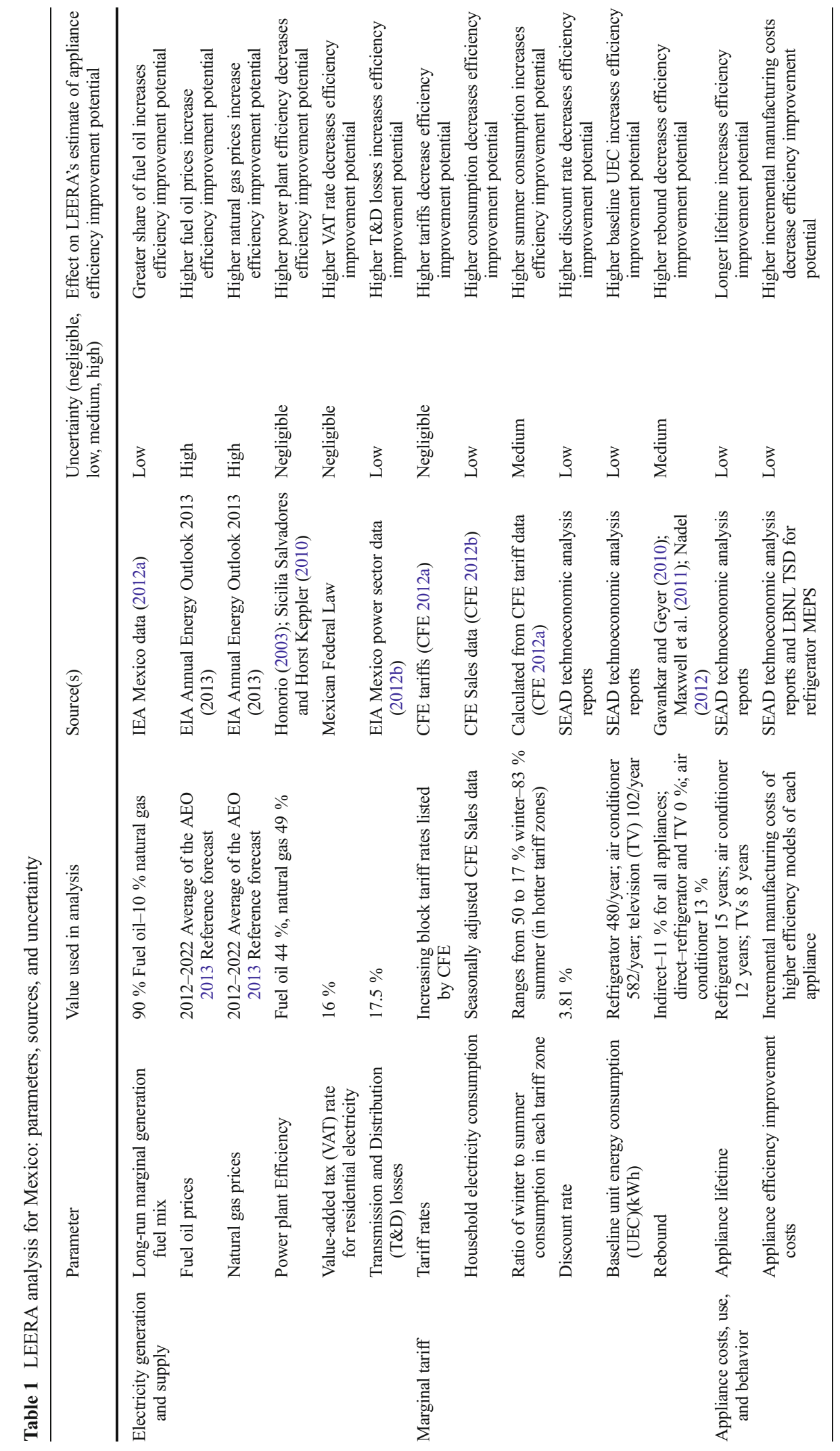




\section{Discussion}

The LEERA model can support financial incentive program implementation in a number of ways. It can show how much, if any, appliance efficiency improvements can be achieved through financing incentives with avoided subsidy payments at a zero or positive net cash flow impact to the government. In turn, this information can help inform incentive levels and incentive program design. For example, LEERA can calculate the appliance efficiency improvement potential from selffinancing for upstream, midstream, or downstream programs. If program administrative costs are known, it can estimate the efficiency improvement potential and the share of self-financing that will go toward these costs. We also plan to extend LEERA to quantify the efficiency-induced incentive financing potential from avoided additions to generation capacity and reduced pollution from the energy system. Importantly, we can apply the model to quantify such self-financing potential for energy efficiency within the business models of privately owned utilities that are common in the USA and Europe.

LEERA could also be used to support standards and labeling programs. For example, LEERA's calculation of efficiency-induced subsidy savings can be added to other consumer cost effectiveness metrics to calculate the national cost effectiveness of strengthening MEPS. Where standards are in place, LEERA can be used to compare existing MEPS with higher efficiency levels that could be obtained at zero net cash flow impact to the government.

Finally, this model allows policymakers to compare and contrast the savings, both energy and financial, and the drivers of those savings, for different end uses. In countries that subsidize residential electricity - those contemplating implementation of financial incentive programs as well as those with programs in place-LEERA can be used to help policymakers implement and improve financial incentive programs. We plan several improvements to LEERA: developing the ability to analyze the impacts and implications of peak consumption and cross subsidization and linking LEERA with LBNL's Bottom Up Energy Analysis System (BUENAS) (McNeil et al. 2013) to estimate macro impacts of using avoided subsidies to finance incentives.

\section{Conclusion}

Many countries around the world, including a number of emerging economies, subsidize electricity consumption, which promotes increased and inefficient energy consumption. Countries that subsidize electricity often find it politically difficult to lower or eliminate subsidies and are frequently unable to strengthen MEPS for economic and political reasons. In this environment, governments have an opportunity to use efficiency-induced savings in subsidy payments to self-finance appliance incentive programs that improve end-use energy efficiency. The LEERA model supports the design of such incentive programs down to the level of specific appliance models.

In the case of Mexico, we find that savings from avoided subsidy payments can finance incentives that cover the entire incremental manufacturing cost of refrigerators that are $29 \%$ more efficient than baseline models. In the case of LED-LCD TVs, the full incremental cost of models that are $36 \%$ more efficient than baseline LED-LCD TVs could be financed with just half of the savings from avoided subsidies. For room ACs, revenue from avoided subsidies could finance an incentive that would cover about one third of the incremental manufacturing cost of a $10 \%$ efficiency improvement. We assess the sensitivity of our results to key parameters and find the results for all three appliances to be robust.

Acknowledgments This work was funded by the Bureau of Oceans and International Environmental and Scientific Affairs, US Department of State, and administered by the US Department of Energy in support of the Super-efficient Equipment and Appliance Deployment (SEAD) initiative through the US Department of Energy under contract no. DE-AC02-05CH11231. We thank the entire US SEAD team. In particular, we thank Nihar Shah, Won Young Park, Michael McNeil, and Virginie Letschert for their assistance in this work. From Mexico, we thank Rodrigo Gallegos for advising the development of the model.

Open Access This article is distributed under the terms of the Creative Commons Attribution License which permits any use, distribution, and reproduction in any medium, provided the original author(s) and the source are credited.

\section{References}

Abhyankar, N., \& Phadke, A. (2012). Impact of large-scale energy efficiency programs on utility finances and consumer tariffs in India. Energy Policy, 43, 308-326. 
AEO. (2013). Annual Energy Outlook 2013. Washington, DC: U.S. Energy Information Administration.

Bacon R, Ley E, Kojima M (2010) Subsidies in the energy sector: an overview. World Bank

Badcock, J., \& Lenzen, M. (2010). Subsidies for electricitygenerating technologies: a review. Energy Policy, 38, 50385047. doi:10.1016/j.enpol.2010.04.031.

Bouton S, Creyts J, Kiely T, et al. (2010) Energy efficiency: a compelling global resource. McKinsey\&Company

CFE (2012a) Tarifas-CFE. http://app.cfe.gob.mx/Aplicaciones/ CCFE/Tarifas/Tarifas/tarifas_casa.asp. Dec 2012a

CFE (2012b) Estadística de Ventas-CFE. http://app.cfe.gob.mx/ Aplicaciones/QCFE/EstVtas/. Accessed 2 Apr 2013b

Dale, L., Antinori, C., McNeil, M., McMahon, J. E., \& Sydny Fujita, K. (2009). Retrospective evaluation of appliance price trends. Energy Policy, 37(2), 597-605. doi:10.1016/j.enpol. 2008.09.087.

Davis L, Fuchs A, Gertler P (2012) Cash for Coolers: how appliance replacement programs affect energy use. Energy Institute at Haas and National Bureau of Economic Research and the Haas School of Business at the University of California, Berkeley, Berkeley, CA

Ellis M (2009) Gadgets and gigawatts: policies for energy efficient electronics. Paris, France

Foster V, Yepes T (2006) Is cost recovery a feasible objective for water and electricity? The Latin American experience. The World Bank

Gadgil, A. J., \& Anjali Sastry, M. (1994). Stalled on the road to the market: lessons from a project promoting lighting efficiency in India. Energy Policy, 22, 151-162. doi:10.1016/03014215(94)90132-5.

Gavankar S, Geyer R (2010) The rebound effect: state of the debate and implications for energy efficiency research. Bren School of Environmental Science and Management, Santa Barbara, CA

Geller, H., Harrington, P., Rosenfeld, A. H., et al. (2006). Polices for increasing energy efficiency: thirty years of experience in OECD countries. Energy Policy, 34, 556-573. doi:10.1016/j. enpol.2005.11.010.

Honorio L (2003) Efficiency in electricity generation. Eurelectric: Union of the Electric Industry, VGB Powertech, Brussels, Belgium

IEA (2012) IEA Statistics: electricity information (2012 edition with 2011 data). II.7,-IV.489, IV.499.

Jaffe, A. B., \& Stavins, R. N. (1994). The energy-efficiency gap: what does it mean? Energy Policy, 22, 804-810. doi:10.1016/ 0301-4215(94)90138-4.

Komives K, Foster V, Halpern J, Wodon Q (2005) Water, electricity, and the poor: who benefits from utility subsidies? World Bank, International Bank for Reconstruction and Development, Washington, DC

Komives K, Halpern J, Foster V, Wodon Q (2006) The distributional incidence of residential water and electricity subsidies. 1-26.
Komives K, Johnson TM, Halpern JD, et al. (2009) Residential electricity subsidies in Mexico: exploring options for reform and for enhancing the impact on the poor. World Bank, International Bank for Reconstruction and Development, Washington, DC

Letschert V, McNeil MA, Lutz W, et al. (2011) Normas de Desempeño Energético Mínimo para Refrigeradores en México: Análisis de Impactos Financieros y Energéticos. Lawrence Berkeley National Laboratory (LBNL), Instituto de Investigaciones Eléctricas Prepared by order of the Collaborative Labeling and Appliance Standards Program (CLASP) for the Comisión Nacional para el Uso Eficiente de la Energía (CONUEE)

Lewis M (2012) The missing link in the oil-price debate - declining crude exports. $1-8$.

Maxwell D, Owen P, McAndrew L (2011) Addressing the rebound effect: final report. European Commission ENV DG, Global View Sustainability Services, France

McNeil M, Letschert V, Rue du Can S, Ke J (2013) Bottom-Up Energy Analysis System (BUENAS) - an international appliance efficiency policy tool. Energy Efficiency 6:191-217217. doi: 10.1007/s12053-012-9182-6

Meier, A., \& Jollands, N. (2007). Mind the gap: quantifying principal-agent problems in the energy efficiency. (C. May, Ed.). Paris: OECD/IEA

Morgan T (2008) Reforming energy subsidies: opportunities to contribute to the climate change agenda. United Nations Environment Programme, Division of Technology, Industry and Economics

Nadel S (2012) The rebound effect: large or small? ACEEE Summer Study

Park, W. Y., Phadke, A., Shah, N., \& Letschert, V. (2011). $T V$ energy consumption trends and energy-efficiency improvement options. Berkeley: Lawrence Berkeley National Laboratory.

Sarkar, A., \& Singh, J. (2010). Financing energy efficiency in developing countries - lessons learned and remaining challenges. Energy Policy, 38, 5560-5571. doi:10.1016/j.enpol. 2010.05.001.

Shah, N., Waide, P., \& Phadke, A. (2013). Cooling the planet: Opportunities for deployment of superefficient room air conditioners. Berkeley: Lawrence Berkeley National Laboratory.

Sicilia Salvadores M, Horst Keppler J (2010) Projected costs of generating electricity-2010 edition. IEA, Nuclear Energy Agency, OECD, Paris, France

(2010) IEA, OPEC, OECD, World Bank joint report: analysis of the scope of energy subsidies and suggestions for the G-20 initiative. 1-81

(2012a) IEA Energy Statistics - electricity for Mexico. http:// www.iea.org/files/503/electricitydata.html. Oct 2012a

(2012b) Mexico power sector data, Energy Information Administration. http://www.eia.gov/files/484/country-data. html. Nov 2012b 